\title{
Fractional Erbium laser in the treatment of photoaging: randomized comparative, clinical and histopathological study of ablative (2940nm) vs. non-ablative (1540nm) methods after 3 months*
}

\author{
Juliano Borges ${ }^{1}$ \\ Carlos Alberto Mandarim-de-Lacerda ${ }^{3}$ \\ DOI: http://dx.doi.org/10.1590/abd1806-4841.20142370
}

Tullia Cuzzi²

Mônica Manela-Azulay²

\begin{abstract}
BACKGROUND: Fractional non-ablative lasers keep the epidermis intact, while fractional ablative lasers remove it, making them theoretically more effective.

OвJECTIVES: To evaluate the clinical and histological alterations induced by fractional photothermolysis for treating photoaging, comparing the possible equivalence of multiple sessions of 1540nm Erbium, to one session of 2940nm Erbium.

MeTHODS: Eighteen patients (mean age 55.9) completed the treatment with three sessions of 1540nm fractional Erbium laser on one side of the face $(50 \mathrm{~mJ} / \mathrm{mB}, 15 \mathrm{~ms}, 2$ passes), and one session of $2940 \mathrm{~nm}$ on the other side $(5 \mathrm{~mJ} / \mathrm{mB}, 0.25 \mathrm{~ms}, 2$ passes). Biopsies were performed before and 3 months after treatment. Clinical, histological and morphometric evaluations were carried out.

RESULTS: All patients presented clinical improvement with no statistically significant difference $(\mathrm{p}>0.05)$ between the treated sides. Histopathology revealed a new organization of collagen and elastic fibers, accompanied by edema, which was more evident with the $2940 \mathrm{~nm}$ laser. This finding was confirmed by morphometry, which showed a decrease in collagen density for both treatments, with a statistical significance for the 2940nm laser ( $\mathrm{p}>0.001)$.

CONCLUSIONS: Three $1540 \mathrm{~nm}$ sessions were clinically equivalent to one $2940 \mathrm{~nm}$ session. The edema probably contributed to the positive results after three months, togheter with the new collagen and elastic fibers organization. The greater edema after the $2940 \mathrm{~nm}$ session indicates that dermal remodeling takes longer than with $1540 \mathrm{~nm}$. It is possible that this histological superiority relates to a more prolonged effect, but a cohort longer than three months is needed to confirm that supposition.
\end{abstract}

Keywords: Collagen; Elastin; Lasers; Skin aging

\section{INTRODUCTION}

In his book "War of the Worlds", George Wells, the famous English science fiction writer, described ray guns that would bring a new concept to people's minds. They were laser prototypes, mentioned before the description of atomical structure by Bohr in 1932 and before the foundations of quantum physics by Einstein in 1972., ${ }^{1,2}$ On that account, the form of light termed "laser" (light amplification stimulated by the emission of radiation), thus appears as a sign of technology and the future prior to its use in specific situations.

In 1959, Maiman developed the first laser machine, and in 1965 Goldman used a laser in Dermatology for the first time, to remove tattoos.,
Lasers became popular in skin treatment in the 1980s, following the description of selective photothermolysis by Anderson and Parish. They soon began to be used in skin rejuvenation. ${ }^{5}$

The first lasers used in photorejuvenation were the ablative $\mathrm{CO}_{2}$ and Erbium types. ${ }^{6,7}$ Despite the good results, their use had limitations, the most significant of which were the side effects associated with the long post-operative period, which was necessary to allow resumption of social activities. ${ }^{8}$

Mainstein's description of fractional photothermolysis in 2004 raised the possibility of treating photoaging with less risk and reduced downtime. ${ }^{9}$ The

Received on 14.12.2012.

Approved by the Advisory Board and accepted for publication on 08.03.2013.

Work performed at the Univesidade Federal do Rio de Janeiro (UFRJ) and Santa Casa de Misericórdia do Rio de Janeiro - Rio de Janeiro (RJ), Brasil.

Conflict of interest: None

Financial funding: None

Santa Casa de Misericórdia do Rio de Janeiro - Rio de Janeiro (RJ), Brazil.

Universidade Federal do Rio de Janeiro (UFRJ) - Rio de Janeiro (RJ), Brazil.

Universidade do Estado do Rio de Janeiro (UERJ) - Rio de Janeiro (RJ), Brazil.

C2014 by Anais Brasileiros de Dermatologia 
fractioning of the laser beams allowed for preservation of areas of healthy skin, which accelerated the healing process.

The first fractional lasers were non-ablative, reaching the dermis but leaving the epidermis untouched. Despite presenting a safer profile, preliminary results were poorer than those of first-generation $\mathrm{CO}_{2}$ and Erbium lasers. In 2007, Hantash and colleagues described ablative fractional lasers, which in theory were more effective in dermal remodeling than non-ablative lasers. ${ }^{10}$ The combination of dermal and epidermal ablation seemed to foster a more robust healing and fibroplasia process, which resulted from greater damage to the skin than that caused by the non-ablative laser. ${ }^{10,11,12}$ Although the results for the methods were not exactly the same, notable improvements in the photoaged skin are described for both methods, following a single session. ${ }^{13-15}$ Due to the lesser amount of tissue damage caused, several nonablative laser sessions are needed to for a comparison in efficacy to a single session of the ablative laser. ${ }^{16-18}$

Most clinical trials demonstrate the efficacy of the methods from an isolated and subjective point of view; few comparisons have been published..$^{13,14,15}$ In a 2008 clinical trial that treated 10 patients with fractional $\mathrm{CO}_{2}$ laser on one side of the face and a $1550 \mathrm{~nm}$ Erbium laser on the other, Weiss and others concluded in their subjective analysis that there was a $75 \%$ improvement using fractional $\mathrm{CO}_{2}$ and a $25 \%$ improvement using the fractional non-ablative laser. ${ }^{19}$ In 2011, Byung and others performed the same comparison in the treatment of wrinkles in four patients and yielded more significant results using fractional $\mathrm{CO}_{2}{ }^{20} \mathrm{In}$ both cases, only a single session of each treatment was performed and, as previously described, many sessions of the non-ablative method are necessary to treat moderate to severe photoaged skin, compared with the ablative method. In 2012, Wattanakrai, Pootongkam and Rojhirunsakool compared the methods in periorbital wrinkles of 22 patients, and suggested that they were equivalent. ${ }^{21}$ Parameters were similar to those we proposed in our study but no histologic observation was performed. Again in 2012, Bas and colleagues published the first histological comparison between these methods. ${ }^{22}$ The main finding was the induction of fibrosis, similar to scar formation in some patients in the group treated with fractional ablative photothermolysis - which was not described in the group treated with non-ablative fractional laser therapy. However, the study was on the treatment of pigmented lesions, without a pre-treatment biopsy, and photoaging was not the target of observation.

Since we thus believe that the differentiation between methods on the treatment of photoaged skin still needs to be scientifically explored, we proposed a prospective, randomized clinical trial comparing 2940nm with 1540nm Erbium. The idea was to compare objectively the effect of multiple fractional nonablative sessions to a single fractional ablative session, observing whether, for the parameters used, the clinical differences between the interventions were relevant and correlated with microscopic changes, which were measured using histology and morphometric quantification of collagen and elastic fibers.

\section{MATERIALS AND METHODS Study Design}

The study is interventionist, of the before/after type, on the clinical and histological modifications inducted by the use of fractional Erbium laser in 30 female patients presenting clinical photoaging of the skin. Patients received fractional non-ablative Erbium (1540nm) on one side of the face, and fractional ablative Erbium $(2940 \mathrm{~nm})$ on the other. The sides on which each treatment was applied were randomly chosen for each patient. Histologic studies examined the epidermis and dermis, with a focus on the collagen and elastic systems. The sample size was chosen according to gender and age homogeneity within the group, while the number of 30 patients was considered adequate for the study's objectives. The project was approved by the HUCFF and Santa Casa da Misericórdia do Rio do Janeiro ethics committee, with the respective protocol numbers of $025 / 09$ and 035/09. All patients signed a free and clarified consent term, with detailed information about the research.

\section{Inclusion Criteria}

Post-menopausal female patients $(\mathrm{n}=30$, aged 50 63), with Fitzpatrick skin types I to IV and Glogau classification II and III with photodamaged skin (clinically represented by hyperpigmentation, wrinkles, alterations in the skin texture and sagging) were selected.

\section{Exclusion Criteria}

Exclusion criteria included women who had used hormone therapy in the previous six months or who had received oral or topical treatment for photoaging in the previous six months. Patients with diseases that compromise the skin's structure (e.g. collagen diseases) or who had photosensitivity or severe comorbidities were also excluded. Inflammatory (e.g. rosacea) or infectious (e.g. herpes simplex) skin diseases with signs of activity were also considered exclusionary criteria.

\section{Treatment}

The study compared treatments applied on either side of the face. The patient received fractional non-ablative Erbium (1540 nm) on one side, and frac- 
tional ablative Erbium $(2940 \mathrm{~nm})$ on the other. The sides on which each treatment was applied were randomly chosen for each patient. A single physician evaluator carried out all treatments. Parameters such as fluency, pulse duration, number of passes, lateral and column overlap was the same for all patients. In both methods, these parameters were the minimum recommended for treatment by the protocol manufacturer. The purpose of using minimum recommended levels was to allow the establishment of reasonably equivalent and comparable parameters, which would not favor either of the methods. Three $1540 \mathrm{~nm}$ and one $2940 \mathrm{~nm}$ sessions were performed, based not only on the minimum number for treatment mentioned by the manufacturer, but also on the literature, which sets out the need for multiple fractional non-ablative sessions, compared with the number of fractional ablative sessions, in the treatment of photoaging. ${ }^{16-18}$ Thus, the study started with the $1540 \mathrm{~nm}$ laser; patients only received the $2940 \mathrm{~nm}$ laser on the other side of the face during the third session (Table 1$)$. Topical $(25 \mathrm{mg} / \mathrm{g}$ lidocaine $+25 \mathrm{mg} / \mathrm{g}$ prilocaine cream) and sublingual (ketorolac tromethamine $10 \mathrm{mg}$ tablet) anesthetics were applied in all sessions, 30 and 15 minutes before treatment, respectively. Patients were instructed not to use any topical medication throughout the study, apart from sunscreen (F30).

\section{Clinical Evaluation}

Individual forms, for taking notes during appointments, were filled in with information on patients and the assessments of medical researchers. Patients were instructed not to use any topical medication - except for SPF 30 sunscreen - during the course of the study. Throughout the research period, patients were seen at the Cosmetic Dermatology outpatient service of the Santa Casa de Misericórdia do Rio do Janeiro. A photographic study was carried out by the medical researcher using a Sony Cyber-shot 10.0 megapixel camera during and after the interventions.

\section{Improvement Scale:}

The degree of improvement was measured by two independent evaluators (i.e. not involved in the study). A Likert-scale assessment was performed for each side treated, separately, after one and after three months following the end of treatment. Patients also performed this same analysis. The evaluation considered four criteria: color (improvement of the rankness), texture (decreased roughness), wrinkles (better if more superficial), firmness (lifting effect).

Questionnaires based on the Likert scale are commonly used for psychometric analyses. ${ }^{23-24}$ Psychometry is the area of psychology related to exact sciences that gathers technics able to measure objectively the impression of the individuals analyzed. That scale was also used by Ciocon $\mathrm{H}$ et al. in a clinical, comparative analysis of different lasers, consisting of a split-face study and, for this reason, we drew on the method to measure the clinical improvement of our patients. ${ }^{25}$ The Likert scale is symmetric and bipolar, based on a central and neutral point. It presents 5 propositions, and the person enquired is asked to select one. Answers are graded, using scores from 0 to 4. In our analysis, "moderate" was considered the neutral point; "no improvement" and "minimal" formed the negative pole; and "considerable" and "great improvement" represented the positive pole (0no improvement, 1- minimal improvement, 2- moderate improvement, 3- considerable improvement, 4great improvement). With the scale based on intervals ( 0 to 4$)$, we analyzed the mean for the answers in each criterion $(\mathrm{n} 1+\mathrm{n} 2+\ldots+\mathrm{n} 18 / 18)$, and for each treatment $\left(1540 \mathrm{~nm}=\mathrm{x}, 2940 \mathrm{~nm}=\mathrm{x}^{\prime}\right)$. The difference between the mean values $\left(x-x^{\prime}\right)$ for each criteria was considered relevant when the $p$ - value, calculated via the $t$-student test with Excel (Microsoft Corp., Redmond, WA), was under 0.05 .

\section{Side Effects}

Side effects (pain; edema; erythema; and desquamation) were evaluated through a visual numeric scale. Pain was assessed by the patients immediately after the procedure, while the other effects were analyzed by two independent physicians, four days after the interventions. The visual numeric scale is a gauging and unidirectional instrument of measurement, commonly used in pain analysis, and it has also been described previously in clinical trials for measuring other side effects related to photoaging treatments. ${ }^{26}$ Therefore, it was the measurement method chosen for our study. On this scale, the grade of intensity varies from 0 to 10 ( 0 - absent; 1 to 3 - light;

TABLE 1: Treatment parameters used in the study

\begin{tabular}{lllllll}
\hline laser & tip & fluency & pulse & $\begin{array}{l}\text { number } \\
\text { of passes }\end{array}$ & overlap & sessions \\
\hline $1540 \mathrm{~nm}$ & $10 \mathrm{~mm}$ & $50 \mathrm{~mJ} / \mathrm{Mb}$ & $15 \mathrm{~ms}$ & 2 & $50 \%$ & 3 \\
$2940 \mathrm{~nm}$ & $10 \mathrm{~mm}$ & $5 \mathrm{~mJ} / \mathrm{Mb}$ & $0.25 \mathrm{~ms}$ & 2 & $50 \%$ & 1 \\
\hline
\end{tabular}


4 to 7 - mild; $>7$ severe). We analyzed the mean value for the answers presented for each collateral effect and each of the methods $\left(1540 \mathrm{~nm}=x, 2940 \mathrm{~nm}=x^{\prime}\right)$. The difference between the mean values $\left(x-x^{\prime}\right)$ with respect to each side effect was considered relevant, when the $\mathrm{p}$ value, calculated trough the t-student test with Excel (Microsoft Corp., Redmond, WA), was under 0.05.

\section{Histological Evaluation:}

The physician filled in a form with the morphological and morphometrical results. Biopsy specimens were taken before and after three months, following the end of the treatments, from both sides of each patient's face. Fragments were obtained from the preauricular region, respecting a distance of $1 \mathrm{~cm}$. The procedure was performed with a $4 \mathrm{~mm}$ punch, while the suture was carried out with 5.0 mononylon (one point). The skin fragments were forwarded for histopathological processing within a maximum period of 12 hours. The material was fixed in 10\% tamponated formol, included in paraffin and submitted to the usual processing routine. In addition to ordinary staining, hematoxilina-eosina (HE) and special stainings, were also performed to assess the collagen (picrosirius), and elastic (orceina), systems. Furthermore, during the pre- and post- treatment biopsies, morphometric studies were conducted in order to quantify fiber density. Routine and special stains were performed at the pathology department of the HUCFF. Skin features were compared before and after the treatment. The study was blind with respect to the sides treated.

\section{Epdermis}

The epidermis was evaluated using hematoxylin-eosin (HE) staining. Alterations found in the epidermal cones and Malpighian layer in the posttreatment period were analyzed.

\section{Collagen System}

Using $\mathrm{HE}$ and picrosirius staining, the degree of elastosis at the dermal-epidermal junction (Grenz zone) and on the papillary dermis, was evaluated.

The elastosis at the dermal-epidermal junction was defined by the presence of hialinyzed and disorganized collagen fibers; and on the papillary dermis, it was characterized by basophilic material spread diffusely in the high dermis, nodules or a band. Changes to the patterns previously observed were described.

\section{Elastic System}

Fibers were evaluated using orcein staining, and attention was paid to the action of radiation, alterations on the superficial plexus (oxitalanic and elauninic), including the diminished density of the fibers or their absence. On the papillary dermis, elastic fibers were considered altered if they were thick and twisty, rather than the normal straight and elongated appearance. Changes to the patterns previously observed were described.

\section{Morphometry}

A morphometric analysis was performed to quantify the densities of the collagen and elastic systems before and after treatment. For this analysis, digital images were obtained from picrosirius and orceinstained sections (JPEG format, 36-bit color, $1280 \times 1024$ pixels) using an LC Evolution camera (Media Cybernetics, Silver Spring, MD, USA) and an Olympus BX51 microscope. The images were analyzed using Image Pro Plus software version 1.7 (Media Cybernetics, Silver Spring, MD, USA), and grouped by shade in order to measure the collagen and elastic fibers before and after treatment. The histogram resulting from this grouping was assessed and the results of the selected pixels were expressed as a percentage of the image's total área. ${ }^{27-28}$ Differences in the amount of collagen and elastin before and after treatment were tested using the student's t-test, and relevant statistical differences corresponded to $\mathrm{p}<0.05$. The study was blind with respect to the sides treated.

\section{RESULTS}

\section{Clinical evaluation}

Only 18 patients completed the study (mean age 55.9). Eight patients left the study after the first $1540 \mathrm{~nm}$ session, complaining of severe pain, and four left after the second $1540 \mathrm{~nm}$ session, for the same reason. Two independent evaluators measured the degree of improvement after the first and third months of treatment. The second evaluation did not differ from the first and did not vary between evaluators (Table 2 and 3, Figure 1). The results for erythema, edema and desquamation were assessed in the week following the last session of treatment, based on a visual numeric scale (0 to 10 ) by two independent investigators, who agreed in all cases. Pain was assessed by the patients immediately after the session (Table 4 and Figure 2).

TABLE 2: Clinical observation from indepentent physicians. The results considered did not differ from the base line after one month and three months.

\begin{tabular}{llll}
\hline parameter & $1540 \mathrm{~nm}$ & $2940 \mathrm{~nm}$ & $\mathrm{p}$-value \\
color & 2.11 & 2.33 & 0.10 \\
texture & 2.17 & 2.22 & 0.33 \\
wrinkles & 2.06 & 2.33 & 0.06 \\
firmness & 1.44 & 1.50 & 0.82 \\
\hline
\end{tabular}



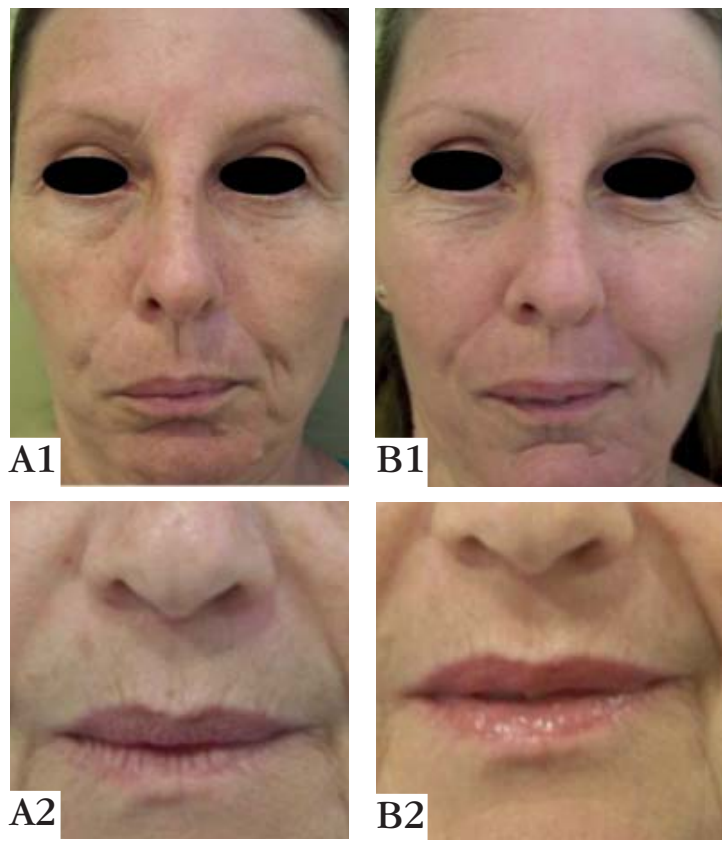

FIGURE 1: Before (A) and after (B) treatment. Patient (1) treated with one $2940 \mathrm{~nm}$ session on the right side of the face and three $1540 \mathrm{~nm}$ sessions on the left side of the face. There was considerable improvement in the color criterion for both tretaments Patient (2) treated with three 1540nm sessions on the right side of the face and one 2940nm sessions on the left side, with considerable improvement in the wrinkles criterion for both treatments. No differences between sides were observed in any of the cases

TABLE 3: Clinical observation, patients. The results considered did not differ from the base line after one month and three months

\begin{tabular}{llll}
\hline parameter & $1540 \mathrm{~nm}$ & $2940 \mathrm{~nm}$ & $\mathrm{p}$-value \\
color & 2.17 & 2.33 & 0.19 \\
texture & 2.11 & 2.22 & 0.16 \\
wrinkles & 2.06 & 2.33 & 0.06 \\
firmness & 1.39 & 1.44 & 0.8 \\
\hline
\end{tabular}

TABLE 4: Side effects: erytema, edema and desquamation, measured by independent physicians after 4 days of treatment. Pain was measured by the patients immediatly after the session. A visual numeric scale was used in this observation

\begin{tabular}{llll}
\hline side effects & $1540 \mathrm{~nm}$ & $2940 \mathrm{~nm}$ & p-value \\
Eythema & 5.00 & 9.00 & $<0.001$ \\
Edema & 2.56 & 9.06 & $<0.001$ \\
desquamation & 5.44 & 8.61 & $<0.001$ \\
Pain & 7.89 & 8.06 & 0.27 \\
\hline
\end{tabular}
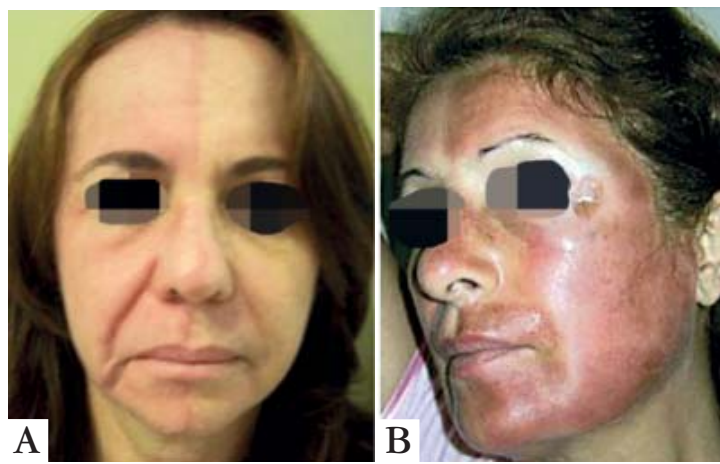

FIgURA 2: The table illustrates erytema, edema, and desquamation, which were more intense on the side treated with the $2940 \mathrm{~nm}$ laser

\section{Histological evaluation}

In analyzing the pre- and post-treatment samples for both lasers used, examination revealed thinning of the Malpighian layer and rectification of epidermal cones, in all cases (Figure 3).

Two areas were considered with regard to the collagen fibers: the subepitelial zone and the papillary dermis. In the 18 cases examined (both sides), the subepithelial area collagen fibers had a homogeneous, hyaline, and anarchic appearance before treatment. Basophilic degeneration of the collagen was also seen in the papillary dermis, in all cases, before treatment. These alterations were attributed to the photoaging process.

Distinct histological features were observed after the treatments. In the subepithelial area fibers were thinner and regularly organized or fragmented (Figure 4). In the papillary dermis, the presence of
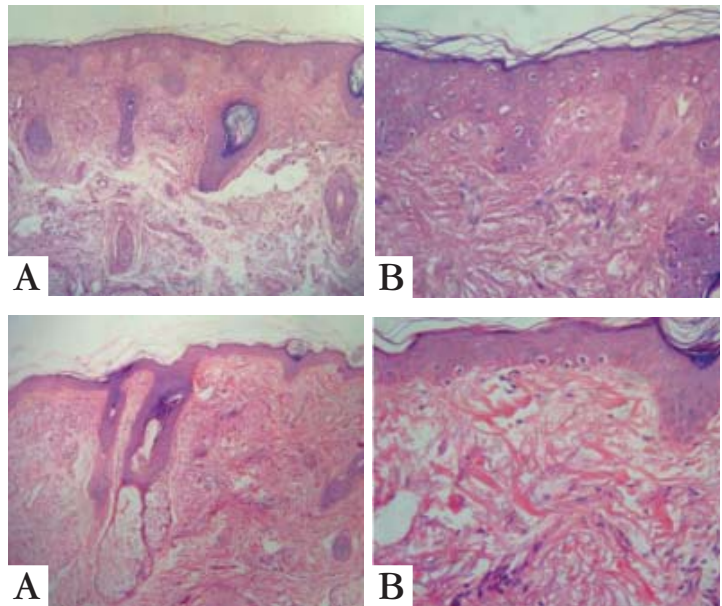

Figura 3: Epidermis stained with H.E., (A) before 10x and 40x; (B) after three months of the 1540nm treatment, 10x and 40x. The cones were considered shorter, the Malpighian layer was considered rectified. These changes were seen after $2940 \mathrm{~nm}$ treatment 

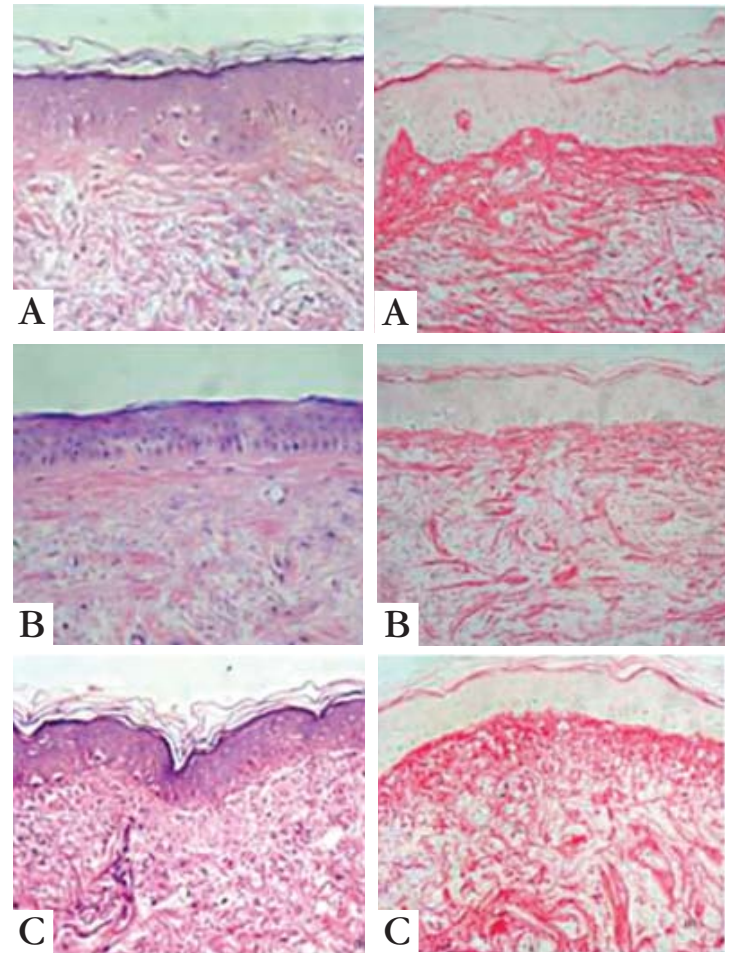

FIGURE 4: New arrangement of collagen fibers seen during the H.E. (top line) and picrosirius staining (botton line). Pre-tretament fibers were hyalinized, thick and distributed irregularly in the Grenz zone (A). After three months, fibers were thinner and appeared regularly (B) or fragmented (C), in the same location. The same patterns were observed after $1540 \mathrm{~nm}$ and $2940 \mathrm{~nm}$ treatments

edema was a significant alteration, observed in all cases after sessions with both types of laser, and characterized by the larger space between the collagen fibers. This edema was more evident in post-2940nm cases than in post-1540nm cases. (Figure 5)

Having examined the elastic fibers before treatment, alterations were observed in all 18 cases studied. Elastic fibers (oxytalanic and elauninic) in the superficial system were diminished, fragmented or absent. Elastic fibers from the high papillary and reticular dermis were thick and fragmented. After the treatment, there was a clear presence of thin elastic fibers on the superficial topography of the superficial elastic system for both treatments. These structures followed a pattern very similar to that of normal oxitalanic and elauninic fibers. The oxytalanic-smile fibers were straight and isolated on the dermal-epidermal junction, perpendicular to its axis, while elauninic-simile fibers were close and parallel to the dermal-epidermal junction. The elastic fibers from the high papillary and reticular dermis after treatment were more numerous and denser in all the cases analyzed (Figure 6).
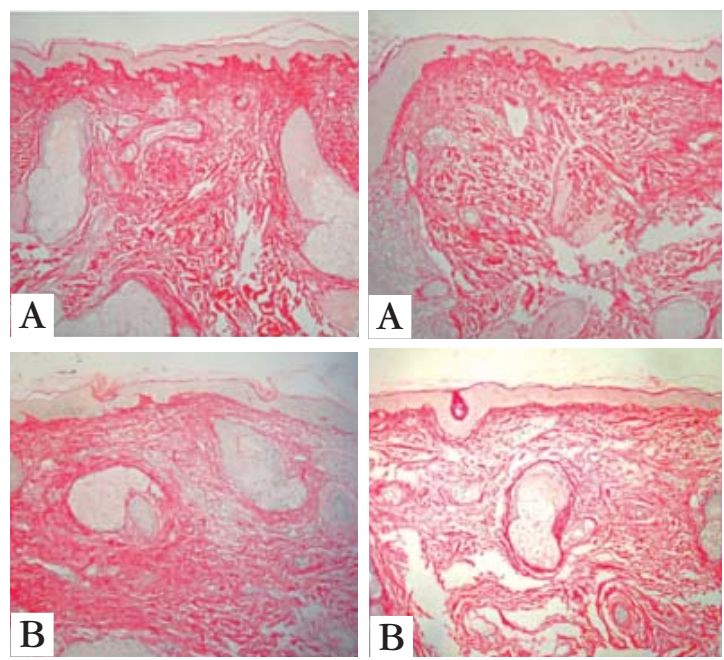

FIGURE 5: Edema in the papillary dermis after treatment seen in plates stained with picrosirius 40x; (A) before and (B) after; 1540nm laser (top line), and $2940 \mathrm{~nm}$ laser (bottom line). The edema was considered greater after $2940 \mathrm{~nm}$ treatment
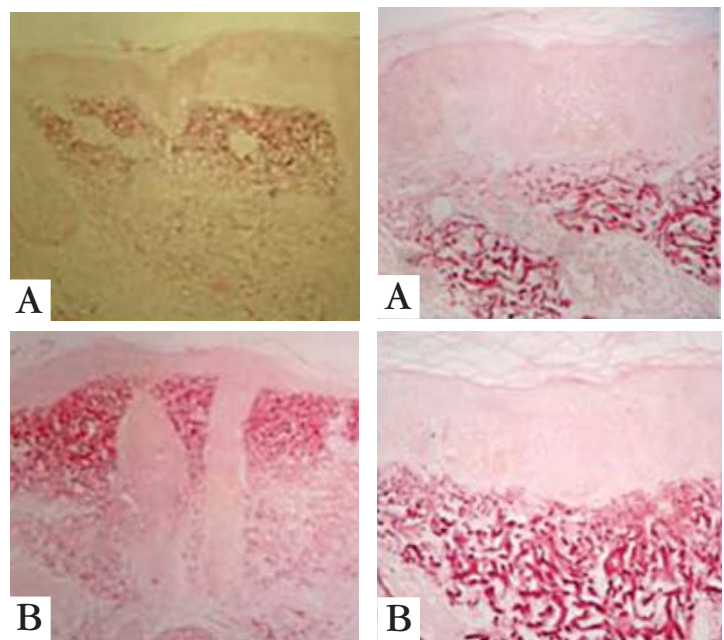

FIGURE 6: New arrangement of elastic fibers. Considerable changes in the elastic fibers before tretament, represented by the absence of fibers in the dermo-epidermical junction and diminushed density of the fibers in the papillary and high reticular dermis (A). Superficial reconstruction of the oxitalanic and elauninic fibers, and papillary and high reticular dermis with more dense fibers were seen after three months of treatment (B); orcein 10x and 40x. The same patterns were observed for both tretments.

\section{Morphometry}

Morphometric studies showed diminished density of collagen fibers after treatments with $1540 \mathrm{~nm}$ and $2940 \mathrm{~nm}$ sessions, though the reduction was greater in $2940 \mathrm{~nm}$ cases. The mean values for the collagen before the treatment were 68.95 for $1540 \mathrm{~nm}$ cases and 72.40 for $2940 \mathrm{~nm}$ cases; and after three 
months of treatment, they were 68.68 and 51.64, respectively. The differences between the means after three months was 0,27 for the $1540 \mathrm{~nm}$ laser, and 20.76 for the $2940 \mathrm{~nm}$ laser. Analyzed via the t-student test, the difference was only considered statistically significant in 2940nm cases ( $p<0,001)$. (Graph 1)

As regards the elastic fibers, the morphometric studies showed increased density after both treatments, though it was greater in $1540 \mathrm{~nm}$ cases. The mean values for the fibers before the treatments were 32.75 for $1540 \mathrm{~nm}$ cases and 34.44 for $2940 \mathrm{~nm}$ cases; and 41.46 and 32.75 after three months, respectively. The differences between the means before and after three months were 8.71 for the $1540 \mathrm{~nm}$ laser and 1.41 for the 2940nm laser. Analyzed through the t-student test, the difference was only considered statistically significant in $1540 \mathrm{~nm}$ cases $(\mathrm{p}<0,001)$. (Graph 2)

\section{DISCUSSION}

There was no statistical significant difference between treatments regarding the four variables measured in the clinical analysis (color, texture, wrinkles, and firmness). ${ }^{12,29,30}$ In our analysis, three fractional non-ablative sessions were clinically equal to one fractional ablative session.

Regarding the side effects analyzed, based on

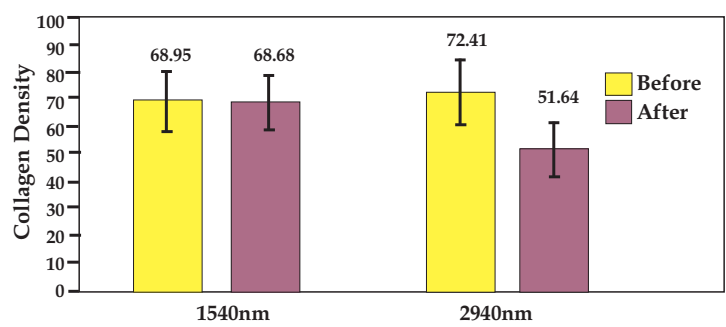

GRAPH 1: Morphometry. Morphometric studies. Graph showing lower density collagen after three months for both treatments, but the difference analyzed through the t-student test was only considered statistically significant for $2940 \mathrm{~nm}$ treatment $(\mathrm{p}<0.001)$

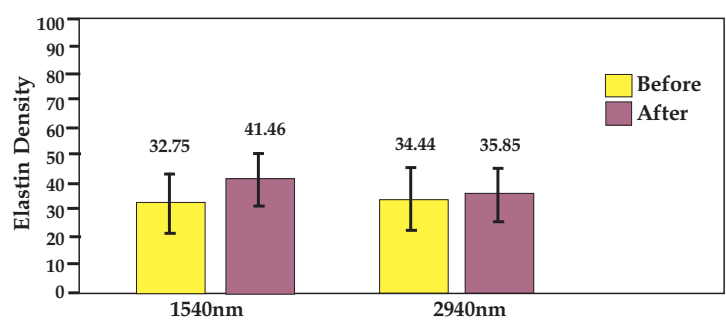

GrAPH 2: showing increase in density of elastic fibers after three months for both treatments but there was statistical significance only for the $1540 \mathrm{~nm}$ treatment $(\mathrm{p}<0.001)$ the literature, we acknowledge that the healing process for the 1540nm Erbium laser was faster than for the 2940nm device, which presented less intense erythema, edema, and desquamation - in some cases resembling treatment with traditional Erbium and $\mathrm{CO}_{2}$ lasers. However, it is important to note that three $1540 \mathrm{~nm}$ sessions were necessary to obtain the same results as one $2940 \mathrm{~nm}$ session, which entails undesired effects on three occasions, though they are less intense. The fact that 12 patients left the study due to severe pain suggests that the anesthesia used was insufficient. This was confirmed by the patients who completed the study, whose assessment of the pain threshold indicated difficulties in exposure to the treatments, despite the sublingual analgesia and topi$\mathrm{cal}$ anesthesia. Other anesthetic options are described in the literature: the use of air-cooling systems during the procedure; and nerve blocks (in particular supraorbital, infraorbital, and mental), 15 minutes before the sessions. ${ }^{33-34}$ Nevertheless, in contrast with this study's findings, many clinical trials with fractional lasers concur that pre-treatment topical anesthetics are sufficient to perform the procedure. ${ }^{35-37}$

Our study was not limited to a clinical comparison between methods. Since we regard subjective analysis as insufficient, histological and morphometrical studies were conducted, geared towards a more objective study. Findings were consistent with the histological effects from fractional ablative and non-ablative photothermolysis, described separately in studies regarding the epidermis and collagen..$^{9,10,36,38-41}$ Although it is non-ablative, according to histological studies, the $1540 \mathrm{~nm}$ laser was able to alter the epidermis as much as the $2940 \mathrm{~nm}$ ablative laser. Further, the hialinyzed collagen present in the Grenz zone, linked to photoaging, was replaced by fibers arranged differently from what had been previously observed. This occurred with both treatments, suggesting neocollagenesis. Rarely studied in previous histopathological analyses, there are few references to the effects of lasers on the architecture of the elastic system. The analysis of those fibers in serial biopsies during the three months after fractional non-ablative photothermolysis in 12 patients did not demonstrate any changes in the post-treatment arrangement. ${ }^{40}$ Another analysis that used serial biopsies during a year of fractional $\mathrm{CO}_{2}$ laser use was consistent with the present study, demonstrating a new arrangement of elastic fibers after three months, as well as an increased expression of elastin for up to one year after treatment. ${ }^{42}$ No long-term comparative analysis involving elastic fibers and fractional photothermolysis was found. Nevertheless, the new fiber arrangement observed in this study suggests reconstitution of the superficial elastic system, similar in both treatments tested. 
All previous reports on neocollagenesis induced by the methods studied were qualitative, whereas we conducted morphmetrical studies on collagen and elastic systems. Despite the great resemblance between the alterations induced by both methods, the quantitative analysis confirmed the only relevant difference in the subjective analysis of the slides: the greater edema on the dermis induced by the $2940 \mathrm{~nm}$ laser, compared with that provoked by the $1540 \mathrm{~nm}$ laser. The edema, characterized histopathologically by the greater space between the collagen fibers, was corroborated by morphometric data, which indicated diminished density of collagen fibers, after both methods, though it was only statistically relevant for the $2940 \mathrm{~nm}$ laser. The elastic fibers that appeared denser, suggetsing superficial reconstruction, in a similar manner to the histopathology, in both methods, showed an increased density that was only statistically relevant in cases following $1540 \mathrm{~nm}$ treatment, which also corroborated the greater edema found in cases treated with the 2940nm laser.

Studies on photoaging show that collagen degeneration due to radiation, correlates directly with the level of hydration of the dermis, which is generally smaller the more fibroblasts decrease. ${ }^{43-46}$ Hence, we correlated the edema and dermal remodeling as being directly proportional. It was inferred that the $2940 \mathrm{~nm}$ laser showed, on a histological level, a greater capacity for transformation, as it provoked greater edema than the 1540nm laser. Unlike the studies conducted to date, we thus inferred that in a period of three months, the edema joins the neocolagenesis and neoelastogenesis in the positive effects on wrinkles and firmness. ${ }^{40,41,47}$ None of the histological studies with fractional lasers conducted to date mention edema after three months. This alteration is mentioned as a histopathological finding that has an acute influence on the healing process, instigated by the therapy under analysis, with complete resolution after seven days, concentrated mainly on the basal layer, rather than the papillary dermis. ${ }^{40,49,50}$ The best characterization for this finding, which represented a shortcoming for the study, involves analysis of other elements from the extracellular matrix, possibly glicosaminoglicans, seen via alcian blue staining, which has not been carried out thus far. Another limitation of this study is the dropout rate, which reduced the number of patients analyzed by $40 \%$. Furthermore, the lack of long-term follow-up (6-12 months) makes it impossible to draw conclusions about the actual relevance of the interventions.

\section{CONCLUSION}

In conclusion, both methods proved to be effective from a clinical perspective, inducing histological changes in the dermal pattern previously seen, though these alterations occurred within a threemonth period and only studies lasting 6-12 months can provide conclusions on the actual impact of this treatment on the group examined. Both were considered equally painful, but the $1540 \mathrm{~nm}$ laser entailed fewer collateral effects. The high dropout rate observed throughout the treatment, due to unbearable pain, casts doubt over the actual worth of the treatment and the anesthetic method applied. Although ablative treatment was considered more effective from a histological perspective, three $1540 \mathrm{~nm}$ sessions were clinically equivalent to one $2940 \mathrm{~nm}$ session, in the age group examined. It is possible that the histological superiority is correlated with more prolonged effects, though a cohort longer than three months would be needed to confirm that supposition. 


\section{REFERENCES}

1. Wells HG. The War of the Worlds. London: William Heinemann; 1898. 303 p.

2. Wheeland RG, McBurney E, Geronemus RG. The role of dermatologists in the evolution of laser surgery. Dermatol Surg. 2000;26:815-22.

3. Maiman TH. Biomedical lasers evolve toward clinical applications. Hosp Manage. 1966;101:39-41.

4. Goldman L, Wilson RG, Hornby P, Meyer RG. Radiation from Q-switched ruby laser: effect of repeated impacts of power output of 10 megawatts on a tattoo of man. $J$ Invest Dermatol. 1965;44:69-71.

5. Anderson RR, Parrish JA. Selective photothermolysis: precise microsurgery by selective absorption of pulsed radiation. Science. 1983;220:524-7.

6. David LM. Laser vermilion ablation for actinc chelitis. J Dermatol Surg Oncol. 1985:11:605-8.

7. Alster TS. Cutaneous resurfacing with $\mathrm{CO} 2$ and Erbium: YAG lasers: preoperative, intraoperative, and postoperative considerations. Plast Reconstr Surg. 1999;103:619-32.

8. Houk LD, Humphreys T. Masers to magic bullets: an update history of lasers in dermatology. Clin Dermatol. 2007;25:434-42.

9. Manstein D, Herron GS, Sink RK, Tanner H, Anderson RR. Fractional photothermolysis: a new concept for cutaneous remodeling using microscopic patterns of thermal injury. Lasers Surg Med. 2004;34:426-38.

10. Hantash BM, Bedi VP, Kapadia B, Rahman Z, Jiang K, Tanner H, et al. In vivo histological evaluation of a novel ablative fractional resurfacing device. Lasers Surg Med. 2007;39:96-107.

11. Helbig D, Paasch U. Molecular changes during skin aging and wound healing after fractional ablative photothermolysis. Skin Res Technol. 2011;17:119-28.

12. Geronemus RG. Fractional photothermolysis: current and future aplications. Lasers Surg Med. 2006;38:169-76.

13. Tierney $\mathrm{EP}$, Hanke $\mathrm{CW}$. Ablative fractionated $\mathrm{CO} 2$, laser resurfacing for the neck: prospective study and review of literature. J J Drugs Dermatol. 2009;8:723-31.

14. Gotkin RH, Sarnoff DS, Cannarozzo G, Sadick NS, Alexiades-Armenakas M. Ablative skin resurfacing with a novel microablative CO2 laser. J Drugs Dermatol. 2009:8:138-44.

15. Clementoni MT, Gilardino P, Muti GF, Beretta D, Schianchi R. Non-sequential fractional ultrapulsed $\mathrm{CO} 2$ resurfacing of photoaged facial skin: preliminary clinical report. J Cosmet Laser Ther. 2007;9:218-25.

16. Trelles MA, Mordon S, Velez M, Urdiales F, Levy JL. Results of fractional ablative facial skin resurfacing with erbium:yttrium-aluminium-garnet laser 1 week and 2 months after one single treatment in 30 patients. Lasers Med Sci. 2009;24:186-94.

17. Ribé A, Ribé N. J Neck skin rejuvenation: histological and clinical changes after combined therapy with a fractional non-ablative laser and stabilized hyaluronic acid-based gel of non-animal origin. J Cosmet Laser Ther. 2011;13:154-61.

18. Chan NP, Ho SG, Yeung CK, Shek SY, Chan HH. The use of non-ablative fractional resurfacing in Asian acne scar patients. Lasers Surg Med. 2010;42:710-5.

19. Weiss R, Weiss M, Beasley K. Prospective split-face trial of a fixed spacing array computed scanned fractional CO2 laser versus hand scanned 1550nm fractional for rhytides. American Society for Lasers Medicine and Surgery Conference, April 2008, Kissimmee, FL.

20. Oh BH, Hwang YJ, Lee YW, Choe YB, Ahn KJ. Skin characteristics after fractional photothermolysis. Ann Dermatol. 2011;23:448-54.

21. Wattanakrai P, Pootongkam S, Rojhirunsakool S. Periorbital Rejuvenation with Fractional 1550nm Ytterbium/Erbium Fiber Laser and Variable Square Pulse 2940nm Erbium:YAG laser in Asians: A Comparision Study. Dermatol Surg. 2012;38:610-22.

22. Wind BS, Meesters AA, Kroon MW, Beek JF, van der Veen JP, van der Wal AC, et al. Formation of fibrosis after nonablative and ablative fractional laser theraphy. Dermatol Surg. 2012;38:437-42.

23. Likert R. A technique for measurment of attitudes, Arch Psychol. 1932;140:1-55.

24. Derstine PL. Implementing goals for non-cognitive outcomes within a basic science course. Acad Med. 2002;77:931-2.

25. Ciocon DH, Engelman DE, Hussain M, Goldberg DJ. A split-face comparision of two ablative fractional carbon dioxide lasers for treatment of photodamaged facial skin. Dermatol Surg. 2011;37:784-90

26. Issa MC, Piñeiro-Maceira J, Vieira MT, Olej B, Mandarim-de-Lacerda CA, Luiz RR, et al. Photorejuvenation with Topical Methyl Aminolevulinate and Red Light: A Randomized, Prospective, Clinical, Histopathologic, and Morphometric Study. Dermatol Surg. 2010;36:39-48.

27. Mandarim-de-Lacerda CA, Fernandes-Santos C, Aguila MB. Image analysis and quantitative morphology. Methods Mol Biol. 2010;611:211-25.
28. Manela-Azulay M, Cuzzi T, Pinheiro J, Azulay DR, Bottino G. Objective methods for analyzing outcomes in research studies on cosmetic dermatology. An Bras Dermatol. 2010;85:65-71.

29. Brightman LA, Brauer JA, Anolik R, Weiss E, Karen J, Chapas A, et al. Ablative and Fractional ablative Lasers. Dermatol Clin. 2009;27:479-89,vi-vii.

30. Berlin AL, Hussain M, Phelps R, Goldberg DJ. A Prospective Study of Fractional Scanned Nonsequential Crabon Dioxide Laser Resurfacing: A Clinical and Histopathologic Evaluation. Dermatol Surg. 2009;35:222-8.

31. Fisher GH, Kim KH, Bernstein LJ, Geronemus RG. Concurrent use of handhels forced cold air device minimized patient discomfort during fractional photothermolysis. Dermatol Surg. 2005;31:1242-3.

32. Laubach H, Chan HH, Rius F, Anderson RR, Manstein D. Effects of skin temperature on lesion size in fractional photothermolysis. Lasers Surg Med. 2007;39:14-8.

33. Hunzeker CM, Weiss ET, Geronemus RG. Fractionated carbon resurfacing: our experience with more than 2,000 treatments. Aesthet Surg J. 2009;29:317-22

34. Alam M, Hsu T, Dover J, Wrone D and Arndt K. Nonablative Laser and Light Treatments: Histology and Tissue Effects- A Review. Lasers Surg Med. 2003;33:30-9.

35. Naouri M, Atlan M, Perrodeau E, Georgesco G, Khallouf R, Martin L, et al. High Resolution Ultrasound Imaging to Demonstrate and Predict Efficacy of Carbon Dioxide Fractional Resurfacing Laser Treatment. Dermatol Surg. 2011;37:596-603.

36. Berlin AL, Hussain M, Phelps R, Goldberg DJ. A Prospective Study of Fractional Scanned Nonsequential Crabon Dioxide Laser Resurfacing: A Clinical and Histopathologic Evaluation. Dermatol Surg. 2009;35:222-8..

37. Jih MH, Kimyai-Asadi A. Fractional Photothermolysis: a review and update. Semin Cutan Med Surg. 2008;27:63-71

38. Fitzpatrick RE, Smith SR, Sriprachya-anunt S. Depth of vaporization and effect of pulse stacking with a high-energy pulsed carbon dioxide laser. J Am Acad Dermatol. 1999;40:615-22.

39. Tierney EP, Kouba DJ, Hanke CW. Review of fractional photothermolysis: treatment indications and efficacy. Dermatol Surg. 2009;35:1445-61.

40. Laubach HJ, Tannous Z, Anderson RR, Manstein D. Skin responses to fractional photothermolysis. Lasers Surg Med. 2006;38:142-9.

41. Dainichi T, Ueda S, Fumimori T, Kiryu H, Hashimoto T. Skin tightening effect using fractional laser treatment II: a pilot animal study on skin remodeling. Dermatol Surg. 2010;36:71-5.

42. Xu XG, Luo YJ, Wu Y, Chen JZ, Xu TH, Gao XH, et al. Immunohistological evaluation of skin responses after treatment using a fractional ultrapulse carbon dioxide laser on back skin. Dermatol Surg. 2011;37:1141-9.

43. Varani J, Warner RL, Gharaee-Kermani M, Phan SH, Kang S, Chung JH, et al. Vitamin A Antagonizes Decreased Cell Growth and Elevated Collagen-degrading Matrix Metalloproteinase and Stimulates Collagen Accumulation in Naturally Aged Human Skin. J Invest Dermatol. 2000;114:480-6.

44. Fisher GJ, Kang S, Varani J, Bata-Csorgo Z, Wan Y, Datta S, et al. Mechanisms of Photoaging and Chronological Skin Aging. Arch Dermatol. 2002;138:1462-70.

45. Röck K, Grandoch M, Majora M, Krutmann J, Fischer JW. Collagen Fragments Inhibit Hyaluronan Synthesis in skin fibroblasts in response to ultraviolet B (UVB). J Biol Chem. 2011;286:18268-76.

46. Oh JH, Kim YK, Jung JY, Shin JE, Kim KH, Cho KH, Intrinsic aging and photoaging dependent level changes of glycosaminoglycans and their correlation with water content in human skin. J Dermatol Sci. 2011;62:192-201.

47. Hantash BM, Bedi VP, Chan KF, Zachary CB. Ex-vivo histological characterization of anonvel ablative fractional resurfacing device. Lasers Surg Med. 2007;39:87-95.

48. Rahman Z, MacFalls H, Jiang K, Chan KF, Kelly K, Tournas J, et al. Fractional deep dermal ablation induces tissue tightening. Lasers Surg Med. 2009;41:78-86.

49. Orringer JS, Rittié L, Baker D, Voorhees JJ, Fisher G. Molecular mechanisms of nonablative fractionated laser resurfacing. Br J Dermatol. 2010;163:757-68.

50. Prignano F, Bonciani D, Campolmi P, Cannarozzo G, Bonan P, Lotti T. A study of fractional CO2 laser resurfacing: the best fluences through a clinical, histological, and ultrastructural evaluation. J Cosmet Dermatol. 2011;10:210-6.
MAILING ADDRESS:
Juliano Borges
Rua Otávio Correia, 448-102 - Urca
22291-180 - Rio de Janeiro - RJ
Brazil
E-mail: julianoborges1@yahoo.com

How to cite this article: Borges J, Cuzzi T, Mandarim-de-Lacerda CA, Manela-Azulay M. Fractional Erbium laser in the treatment of photoaging: randomized comparative, clinical and histopathological study of ablative (2940nm) vs. non-ablative (1540nm) methods after 3 months. An Bras Dermatol. 2014;89(2):67-71. 